\title{
BMJ Global Health Health research in humanitarian crises: an urgent global imperative
}

\author{
Brandon A Kohrt, ${ }^{1}$ Amit S Mistry (D) , ${ }^{2}$ Nalini Anand, ${ }^{2}$ Blythe Beecroft, ${ }^{2}$ \\ Iman Nuwayhid ${ }^{3}$
}

To cite: Kohrt BA, Mistry AS, Anand N, et al. Health research in humanitarian crises: an urgent global imperative. BMJ Global Health 2019;4:e001870. doi:10.1136/ bmjgh-2019-001870

\section{Handling editor Eduardo}

Gómez

Received 25 July 2019

Revised 4 September 2019

Accepted 12 September 2019
Check for updates

\section{(c) Author(s) (or their} employer(s)) 2019. Re-use permitted under CC BY-NC. No commercial re-use. See rights and permissions. Published by BMJ.

${ }^{1}$ Department of Psychiatry and Behavioral Sciences and Department of Global Health, George Washington University, Washington, DC, USA

${ }^{2}$ Fogarty International Center, $\mathrm{NIH}$, Bethesda, Maryland, USA ${ }^{3}$ Faculty of Health Sciences, American University of Beirut, Beirut, Lebanon

Correspondence to Dr Amit S Mistry; amit.mistry@nih.gov

\section{ABSTRACT}

Globally, humanitarian crises-such as armed conflict, forced displacement, natural disasters and major disease outbreaks-affect more people today than at any point in recorded history. These crises have immense acute and long-term health impacts on hundreds of millions of people, predominantly in low and middle-income countries (LMIC), yet the evidence base that informs how humanitarian organisations respond to them is weak. Humanitarian crises are often treated as an outlier in global health. However, they are an increasingly common and widespread driver of health that should be integrated into comprehensive approaches and strategies, especially if we hope to achieve ambitious global health targets such as the Sustainable Development Goals. The academic research community can play an important role in addressing the evidence gap in humanitarian health. There are important scientific questions of high public health relevance that can only be addressed by conducting research in humanitarian settings. While working in these settings is uniquely challenging, there are effective strategies that can be employed, such as using flexible and adaptive research methodologies, partnering with nongovernmental organisations and other humanitarian actors and devoting greater attention to issues of research ethics, community engagement, local LMIC-based partners, building humanitarian research capacity and collaborating across disciplines.

\section{INTRODUCTION}

Today, more people are impacted by humanitarian crises than at any point in recorded history. One in six children lives in close proximity to a conflict zone ${ }^{1}$ while 70.8 million people have been forced to flee from their homes-the highest number since World War II. ${ }^{2}$ Natural disasters, on average, affect roughly 200 million people each year. ${ }^{3}$ The 2014-2016 Ebola outbreak in West Africa demonstrated how an infectious disease outbreak can become an international humanitarian crisis. In recent years, humanitarian crises have become more frequent, more protracted, more complex and more costly, stretching an underfunded humanitarian response community to its limits. ${ }^{45}$
Summary box

Humanitarian crises have immense short and longterm health impacts, yet the evidence base for best healthcare practices in humanitarian settings is limited.

- The global health research community can and should play a significant role in addressing the evidence gap in humanitarian health by studying important scientific questions that can only be addressed by conducting research in humanitarian settings.

- There are several effective strategies that can be used to address the many unique challenges of conducting research in humanitarian crises.

- Global health researchers, research funders, policymakers and practitioners should recognise humanitarian health as integral to progress in global health.

- Research in these challenging settings requires consideration of flexible methodologies, research ethics, multisector partnerships, engagement with available public health information systems, collaboration with local communities and leaders, research capacity and multidisciplinary approaches that cut across multiple health domains.

Humanitarian crises include: (1) man-made disasters, including armed conflict, forced displacement and refugee crises; (2) natural disasters, such as floods, hurricanes, earthquakes and droughts; and (3) major infectious disease outbreaks. Often, multiple types of crises occur simultaneously, such as armed conflict or natural disasters combined with famine and disease outbreaks. All of these types of crises have a severe effect on human health, with a disproportionate impact on disadvantaged populations and people in low and middle-income countries (LMIC) who are impacted by humanitarian crises more often but are generally less prepared for them.

Immediately following the onset of a crisis, acute health problems of trauma, injury and the spread of infectious disease are the primary concern of humanitarian response organisations. However, humanitarian crises 
also have many long-term impacts on health and the environment. As health systems are disrupted, damaged and/or overwhelmed, healthcare is challenging to deliver. For many, crises also mean the loss of livelihoods, displacement from their homes and communities, emotional distress and social suffering. Health problems are exacerbated for people with pre-existing health conditions and new health issues arise. Humanitarian crises impact almost every aspect of health, including but not limited to: maternal and child health; infectious disease; injury and other physical trauma; sexual and reproductive health; nutrition; and noncommunicable diseases such as diabetes, heart disease and mental health.

What is the role of the research community in addressing the health impacts of humanitarian crises? How can research help improve the quality of health services during and after crises? Are there important scientific questions that can only be addressed by research in these contexts? How do researchers work in these challenging settings without impeding humanitarian assistance and ensure that research findings benefit affected populations? How are successful, equitable and sustainable research collaborations built with local researchers in humanitarian settings? Is there an advocacy role for health researchers?

To explore these questions, the Fogarty International Center at the US National Institutes of Health convened a committee of experts from research and humanitarian communities, chaired by the authors of this paper. The resulting project, Advancing Health Research in Humanitarian Crises, brought together a broad range of stakeholders and experts with diverse experiences in different health areas and from many geographic regions, especially LMICs, to share lessons learnt and explore how to catalyse timely, high-quality, ethical and actionable research in humanitarian crises and encourage uptake of evidence into humanitarian policy and practice.

To date, this project has consulted 179 individuals from more than 80 organisations representing humanitarian, research, policy and research funding communities. Building on these consultations, the challenges and opportunities for health research in humanitarian crises were discussed further at a workshop hosted by the Fogarty International Center in April 2018. This paper highlights several of the findings and learnings from the workshop and subsequent analysis, focusing on a few key messages:

1. Humanitarian health is integral to global health.

2. The global health research community plays a critical role in addressing the significant evidence gap in humanitarian health.

3. There are important scientific questions of high public health relevance that can only be answered by research in humanitarian settings.

4. While humanitarian health research is uniquely challenging, many effective strategies and approaches can be used.
HUMANITARIAN HEALTH IS INTEGRAL TO GLOBAL HEALTH

Developing global health strategies without significant attention to the humanitarian context is like building a hospital without an emergency room. Far too often, humanitarian crises are treated as outliers or exceptions, and subsequently are neglected in the formulation of health programmes and strategies. The unfortunate reality is that humanitarian crises are common and widespread experiences driving human health worldwide. If health in fragile contexts is not prioritised by the global health research community, it will be very difficult to achieve ambitious health goals on a global level.

Much of the world made remarkable progress on the Millennium Development Goals (MDG), which United Nations (UN) member states committed to achieving by 2015. However, countries affected by conflict and fragility consistently lagged behind other LMICs on these goals ${ }^{6}$ and none of these countries achieved a single MDG. ${ }^{7}$ The UN's updated 2030 Sustainable Development Goals (SDG) set even more ambitious targets for many healthrelated areas. Populations affected by conflict, such as refugees and internally displaced persons fleeing war, cannot be overlooked if we hope to achieve the SDGs. ${ }^{8}$ Likewise, reducing the impacts of natural disasters and hazards on health is critical to achieving the SDGs, as recognised by the UN Sendai Framework for Disaster Risk Reduction. ${ }^{9}$

For instance, SDG 3-Ensure healthy lives and promote well-being for all at all ages-includes targets for reducing maternal and child mortality. While maternal and child mortality rates are declining globally, they are significantly higher in fragile and conflict-affected countries than in stable countries. ${ }^{7}$ In fact, children in fragile or conflictaffected countries are twice as likely to die before the age of 5 compared with children in other, more stable LMICs. ${ }^{7}$ SDG 3 also includes targets for infectious diseases, which are incredibly difficult to manage in conflict-affected settings as seen in the current Ebola outbreak in the Democratic Republic of Congo, the recent cholera outbreak in Yemen and stalled efforts to eradicate polio in parts of Afghanistan, Pakistan and Nigeria. ${ }^{10}$ Similarly, the economic, political and healthcare crisis in Venezuela is marked by the spread and re-emergence of vectorborne diseases, such as malaria, Chagas disease and dengue, undermining efforts to eradicate these diseases from Venezuela and neighbouring countries. ${ }^{11}$

Other health-related SDG targets, as well as targets related to clean water and hunger, are also much more difficult to achieve in humanitarian settings. Given the increasing frequency and impact of humanitarian crises worldwide, along with their protracted nature, these settings cannot be ignored. Rather, efforts that integrate humanitarian settings into comprehensive approaches are likely to make more significant contributions to global health goals. 


\section{THE NEED FOR RESEARCH IN HUMANITARIAN SETTINGS}

Research is important and often necessary to understanding how to best improve health and health services in humanitarian crises. There are unique scientific questions of high public health relevance that can only be answered through research in humanitarian settings. For example, research can help determine which health interventions are most effective in humanitarian settings, when new or adapted interventions are needed and how to best deliver care in crisis settings. However, not all research questions should be answered in this context'If the research question could be answered in a nonemergency setting, then it should not be answered in an emergency setting,' as recommended by the Inter-Agency Standing Committee (IASC). ${ }^{12}$

Unfortunately, the quantity and quality of evidence used to inform the humanitarian response is severely limited. There are many reasons for this weak evidence base. Organisations and institutions responding to humanitarian crises-including local and regional governments, national and international non-governmental organisations (NGO), and UN agencies-are already overstretched and underfunded. Research is not typically perceived as a priority when immediate survival needs of populations need to be funded and administered. Furthermore, public health information systems, when available, may be disrupted or politically biased during such crises. ${ }^{13}{ }^{14}$ Consequently, there are limited and lost opportunities for systematic data collection, analysis, critical reflection and dissemination to the broader humanitarian community. Humanitarian practice and policy, therefore, are too often based on anecdotal experience, rather than rigorous, scientific research. ${ }^{15}$

Researchers face a number of challenges when conducting health research in humanitarian crises. Most humanitarian crises affect already low-resourced settings. Academic researchers generally do not have the skills or expertise to work in unstable settings, where they must deal with safety and security concerns, political sensitivities, damaged and overwhelmed health systems, and logistical challenges. From a methodological perspective, traditional research designs may not be appropriate for humanitarian crises. For instance, identifying a control group may be impractical or unethical, baseline data may not be available and dynamic settings may require changes to study designs with little notice. Researchers may face ethical dilemmas in balancing urgent health needs with research goals that may have long-term benefits or in obtaining informed consent from extremely distressed and vulnerable populations. On top of these obstacles, humanitarian settings require coordination with myriad local and international actors and stakeholders who are rapidly changing with many only having short-term and limited mandates or missions for humanitarian response. Funding opportunities for humanitarian research are also few and far between.

Therefore, it is not surprising that a recent comprehensive and systematic review of currently available evidence on public health interventions in humanitarian crisis settings found that very little evidence exists, and what does exist is often low quality, with weaknesses in study designs and methods. ${ }^{16}$ The review highlighted notable deficiencies for research related to non-communicable diseases, sexual and reproductive health, and water, sanitation and hygiene. ${ }^{16}$

The lack of research and evidence-based practices in humanitarian crises leads to a reliance on research findings from 'stable'-typically high-income-settings to inform decisions about health interventions. However, health interventions proven to be effective in a stable country cannot simply be 'imported' to a crisis setting where health systems may be damaged, infrastructure is weakened and populations have experienced exceptional trauma. It already takes several years for research evidence to reach clinical practice in stable settings; adapting this evidence for more challenging settings can take much longer.

Developing and evaluating interventions in stable settings and then waiting to test them in humanitarian settings is not an effective or efficient research strategy. Instead, research needs to be done with and for populations affected by humanitarian crises to determine interventions and models of care that are feasible, effective and appropriate for the context. In some cases, testing health interventions in crisis environments is the only way to determine their effectiveness. For example, we cannot fully know if vaccines and therapeutics for Ebola virus are effective without studying them in the context of an actual Ebola outbreak and under strict ethical guidelines. ${ }^{17} 18$

When most research is designed for and conducted with populations in stable and high-income settings, we are neglecting more than 132 million people in need of humanitarian assistance, ${ }^{19}$ who disproportionately face early mortality and excess morbidity. Furthermore, research in humanitarian contexts may ultimately yield models and tools that can then be expanded to nonhumanitarian settings. Just as military medicine has often led to innovations for civilian health ranging from surgery to mental healthcare, humanitarian settings often necessitate innovations that can improve nonemergency care. For example, innovations in mHealth and digital health for emergency settings can also be used to improve care in other settings with access and resource constraints. ${ }^{20}$

Health research in humanitarian crises is needed to ensure that humanitarian action is evidence-based, effective and sets the stage for postcrisis health planning and rehabilitation. Some argue that it is unethical to not conduct research in conflict and crisis settings as the current evidence base is so deficient. ${ }^{21}$ Continuing to use practices that are not contextual and evidence-based may harm affected populations. Additionally, humanitarian responses cannot be expected to achieve optimal health outcomes without a rigorous and scientific evidence base. 


\section{RESEARCH PRIORITIES IN HUMANITARIAN CRISES}

Research should only be conducted in the context of a humanitarian crisis for research questions that cannot be addressed in non-emergency settings. The IASC further recommends that research questions: respond to a recognised gap or need; ensure fair and direct benefits to participants with minimised risks; and include planned dissemination to participants, collaborators and funders. ${ }^{12}$

With these principles in mind, there are many important scientific questions that require research in the context of a humanitarian crisis and several groups have developed research agendas accordingly. Evidence Aid, an international initiative supporting the use of evidence in humanitarian action, consulted a broad range of humanitarian practitioners, policymakers and researchers to identify priority areas of research in need of updated evidence and 4 of the top 10 are related to health: water and sanitation, nutrition and food security, maternal and child health, and mental health. ${ }^{22}$ More detailed humanitarian health research gaps, priority questions and agendas have been articulated in areas such as: neonatal health, ${ }^{23}$ child protection, ${ }^{24}$ mental health and psychosocial support, ${ }^{25}$ non-communicable diseases,${ }^{26}{ }^{27}$ sexual and reproductive health, ${ }^{28}$ ethics ${ }^{29}$ and health systems research. ${ }^{30}$ Table 1 presents several illustrative research questions, some of which are based on the aforementioned research agendas, that can only be addressed in the context of humanitarian crises.

While these questions are focused on humanitarian contexts, studying them may also provide insights that are relevant to public health more generally. For example, mental health outcomes from collective trauma compared with individual trauma can be more effectively studied in a humanitarian crisis. The impact of social networks on risk of depression and post-traumatic stress disorder after bushfires in Australia $^{31}$ can be used to better understand the social patterning of mental illness in non-crisis settings. Similarly, biological pathways associated with resilience

Table 1 Illustrative humanitarian health research questions

\begin{tabular}{|c|c|}
\hline $\begin{array}{l}\text { Type of } \\
\text { research }\end{array}$ & lustrative research questions \\
\hline Methodological & $\begin{array}{l}\text { How do we protect and promote the rights of research participants in humanitarian crises? } \\
\text { What ethical guidelines and IRB procedures should be adopted? Should they differ from ethical guidelines in } \\
\text { stable settings? } \\
\text { How should research methodologies be adapted for humanitarian crises? What new methodological approaches } \\
\text { are needed for humanitarian research? } \\
\text { What are the most effective methodological approaches for evaluating a new health intervention (eg, a new } \\
\text { vaccine) in a humanitarian crisis? }\end{array}$ \\
\hline $\begin{array}{l}\mathrm{De} \\
\mathrm{ep}\end{array}$ & $\begin{array}{l}\text { What are the causes, spreading patterns and risk factors for (a specific disease or health condition) in } \\
\text { humanitarian crises? } \\
\text { What are the stressors faced by populations in humanitarian settings? }{ }^{25} \\
\text { What is the additional burden of neonatal mortality in different emergency situations (eg, conflict, acute vs } \\
\text { protracted, natural disaster)? } \\
\text { How can public health information systems be better leveraged in humanitarian settings for determination of } \\
\text { mortality and morbidity? }{ }^{1314}\end{array}$ \\
\hline Disc & $\begin{array}{l}\text { What new health interventions (eg, treatments, vaccines, technologies, etc.) are needed for humanitarian crises? } \\
\text { Develop and validate strategies to identify preterm babies at the community level by CHWs and family } \\
\text { members. }{ }^{23}\end{array}$ \\
\hline $\begin{array}{l}\text { Intervention } \\
\text { research }\end{array}$ & $\begin{array}{l}\text { What are the most effective mental health and psychosocial interventions for conflict-affected children? }{ }^{39} \\
\text { How effective is (a specific evidence-based health intervention) in a humanitarian setting? } \\
\text { What are the most effective interventions to reduce childhood morbidity and mortality, and improve well-being } \\
\text { after a disaster or in other humanitarian emergencies? } \\
\text { What are the effects of breast feeding promotion interventions, including integrated breast feeding, on breast } \\
\text { feeding rates and duration after a disaster or in other humanitarian emergencies? }{ }^{22}\end{array}$ \\
\hline ientation & $\begin{array}{l}\text { How can evidence-based health interventions developed in stable settings best be delivered or implemented in } \\
\text { humanitarian crises? } \\
\text { What are the most effective ways to culturally adapt existing mental health and psychosocial support } \\
\text { interventions for use after a disaster or in other humanitarian emergencies? }\end{array}$ \\
\hline $\begin{array}{l}\text { Health sys } \\
\text { research }\end{array}$ & $\begin{array}{l}\text { How can the quality of health services in humanitarian settings be improved and sustained? } \\
\text { What attributes favour an adaptive, responsive and resilient healthcare system? } \\
\text { What approaches do people affected by humanitarian crises adopt to successfully gain access to health } \\
\text { Services? } \\
\text { How to get the right balance between emergency service delivery and long-term systems strengthening } \\
\text { What healthcare delivery models work best in humanitarian contexts? And what kind of actors can best } \\
\text { implement such models and deliver the best results? }\end{array}$ \\
\hline
\end{tabular}


after humanitarian crises $^{32}$ can inform physical and mental health promotion for general populations. Research in humanitarian settings can also uniquely examine the interaction of social, ecological, environmental and/or economic factors with multiple domains of health problems through syndemic theory and systems science. ${ }^{33}$

\section{STRATEGIES FOR HUMANITARIAN HEALTH RESEARCH}

For many in the global health research community, the challenges and risks associated with humanitarian health research dampen or outweigh their interest in this field of study. This may also explain the reluctance of funding agencies to invest in such research. Yet, there are a variety of strategies that can be used to address these challenges and mitigate risks. Based on the learning from the Advancing Health Research in Humanitarian Crises project to date, several principles for conducting research in humanitarian crises are highlighted in this section, grouped into principles specific to humanitarian crises and more general principles for LMIC-based research that are especially important in humanitarian settings.

\section{Research strategies specific to humanitarian crises}

Use flexible and adaptive methodologies. Humanitarian crises are unstable, unpredictable environments and as such, researchers should be prepared to adjust study parameters and methodologies as needed. However, researchers should not compromise the rigour or quality of their work as they must ensure that findings are valid and can inform humanitarian practice and policy. This includes conducting randomised controlled trials and other strictly quantitative analysis when feasible. Mixed and qualitative methods should also be considered as they can be equally robust and may be more appropriate for humanitarian settings. For example, qualitative methods can make an important contribution to interpreting mortality estimates, which often have wide confidence interval in humanitarian crises. ${ }^{13}{ }^{14}$ Other research actors, such as funders, ethical review boards and journal publishers, should similarly be aware of the importance of flexible and adaptive methodologies in these settings.

Partner across the humanitarian-academic divide. While humanitarian organisations and academic organisations have extremely different cultures, time frames and missions, partnerships between these two sectors can be especially fruitful in humanitarian health research. Academic institutions are experienced in designing and conducting high-quality studies while humanitarian organisations have the logistical capabilities and relationships with local communities necessary to operate in humanitarian settings. ${ }^{34}$ Collaboration between the two is critical, and often necessary, to produce research that is rigorous and actionable. Notably, several humanitarian NGOs are deepening partnerships with academic research institutions and others already have or are developing their own in-house research capabilities. At the same time, several academic institutions are engaging in humanitarian training, education and research activities with a range of humanitarian actors.

\section{Strategies for conducting research in LMICs that are especially important in humanitarian crises}

Engage with affected populations and communities. Populations affected by crises are especially vulnerable and often severely distressed. They should not be treated solely as research participants, but rather as partners throughout the research process to help ensure that the research is addressing the highest community priorities and is conducted in a culturally sensitive manner. Engaging local communities and affected populations enables community trust, improves research designs and provides a pathway for research dissemination, resulting in higher quality research and more actionable findings.

Local leadership. Whenever possible, local actors-including researchers, national and local NGOs, governments and communities-should lead research efforts, in partnership with the international research and humanitarian communities. If they do not have the capacity to lead these efforts, they should be actively engaged as much as possible. Local partners understand cultural and historical context and are better linked with local communities, and their engagement improves the quality and relevance of research. Political, institutional and societal dynamics are especially important in humanitarian research and local actors are key partners in navigating these factors. ${ }^{35}$ Support to local organisations, such as NGOs, should also consider the sustainability of those organisations and retention of local experts in their home countries. Leadership by local actors increases the sustainability of research efforts beyond crisis events, contributing to preparedness and resiliency against future crises and disasters. For partnerships between international and local researchers to be sustainable and equitable, guiding principles of collaboration need to be established regarding data sharing and ownership, publication and dissemination of findings, compensation for research efforts, opportunities for further training and recognition in social and traditional media. ${ }^{36} 37$

Build local and global humanitarian research capacity. Conducting health research in humanitarian crises is uniquely challenging and as such, requires specialised research skills. Building the capacity of academic and NGO-based researchers in and from regions affected by humanitarian crises leads to better preparedness and resilience to future disasters. It is important for training efforts to focus on the bidirectionality of learning to ensure that researchers from high-income countries gain methodological skills as well as the interpersonal skills and cultural competencies needed to work in challenging humanitarian environments. Ultimately, achieving the goals of local leadership and funding to local organisations will require strengthened local capacity and retention of researchers. Beyond research training, strengthening public health information systems enables valid, reliable and timely data 
Table 2 Selected resources, tools and networks available to humanitarian health researchers

\begin{tabular}{lll}
\hline Organisation & Resource description & Website \\
\hline Evidence Aid & $\begin{array}{l}\text { A collection of systematic reviews that provide } \\
\text { reliable, up-to-date evidence on interventions that } \\
\text { might be considered in the context of natural disasters } \\
\end{array}$ & \\
& and other major healthcare emergencies.
\end{tabular}

United Nations (UN) Global Migration, Health and Development Research https://mhadri.org/

International Organization Initiative (MHADRI) - a global alliance of migration

for Migration (IOM) health researchers and scholars and a platform to

share, collaborate, develop, advocate and disseminate research at the nexus of health and migration.

\begin{tabular}{|c|c|c|}
\hline $\begin{array}{l}\text { Medecins Sans Frontieres } \\
\text { (MSF) }\end{array}$ & $\begin{array}{l}\text { Field research-a free repository of articles based on } \\
\text { the field research of MSF. }\end{array}$ & https://fieldresearch.msf.org/ \\
\hline $\begin{array}{l}\text { National Institutes of } \\
\text { Health (NIH) National } \\
\text { Library of Medicine }\end{array}$ & $\begin{array}{l}\text { Disaster Lit Database for Disaster Medicine and Public } \\
\text { Health-a free collection of disaster medicine and } \\
\text { public health documents. }\end{array}$ & https://disasterinfo.nlm.nih.gov/disaster-lit \\
\hline $\begin{array}{l}\text { NIH National Institute of } \\
\text { Environmental Health } \\
\text { Sciences and National } \\
\text { Library of Medicine }\end{array}$ & $\begin{array}{l}\text { Disaster Research Response (DR2)-a collection of } \\
\text { data collection tools, research protocols, disaster } \\
\text { research news and events, and more. }\end{array}$ & https://dr2.nlm.nih.gov/ \\
\hline $\begin{array}{l}\text { UN Office for the } \\
\text { Coordination of } \\
\text { Humanitarian Affairs } \\
(\mathrm{OCHA})\end{array}$ & $\begin{array}{l}\text { The Humanitarian Data Exchange-an open platform } \\
\text { for sharing data across crises and organisations. }\end{array}$ & https://data.humdata.org/ \\
\hline $\begin{array}{l}\text { Post-Research Ethics } \\
\text { Analysis (PREA) }\end{array}$ & $\begin{array}{l}\text { A research project investigating ethical issues in } \\
\text { health research in humanitarian crises. It aims to } \\
\text { identify good ethical practice from lessons learned in } \\
\text { the field and develop a tool that assists reflection on } \\
\text { ethical issues in humanitarian research. }\end{array}$ & http://www.preaportal.org/ \\
\hline $\begin{array}{l}\text { Nuffield Council on } \\
\text { Bioethics }\end{array}$ & $\begin{array}{l}\text { Research in global health emergencies-a project } \\
\text { exploring how research may be conducted ethically in } \\
\text { global health emergencies. }\end{array}$ & $\begin{array}{l}\text { http://nuffieldbioethics.org/project/global- } \\
\text { health-emergencies }\end{array}$ \\
\hline Elrha & $\begin{array}{l}\text { Research for Health in Humanitarian Crises (R2HC) } \\
\text { - A research funding programme specific to health } \\
\text { research in humanitarian crises, funded by the } \\
\text { UK Department for International Development, } \\
\text { UK National Institute for Health Research, and the } \\
\text { Wellcome Trust. }\end{array}$ & $\begin{array}{l}\text { https://www.elrha.org/programme/ } \\
\text { research-for-health-in-humanitarian-crises/ }\end{array}$ \\
\hline
\end{tabular}

collection during emergencies, improves the quality of research and promotes transparency and accountability in the humanitarian response.

Collaborate across disciplines. Humanitarian crises impact almost all facets of human health. Affected individuals and communities may suffer from multiple conditions simultaneously and as a result, humanitarian responders may be expected to deal with a broad range of health problems. Furthermore, political, social, environmental and economic factors and their effects on health must be considered in humanitarian settings. Researchers should take a multidisciplinary approach across health disciplines and an integrated approach beyond health disciplines, while also being aware of the broader contextual factors affecting study populations.

Leverage existing tools and networks. While very little humanitarian health research is currently being funded and is mostly supporting researchers from outside the affected settings, there are many organisations actively working to address the gap. These efforts, some of which are described in table 2, build relevant capacity and develop resources such as: systematic reviews of humanitarian research; repositories of scientific literature; platforms for sharing humanitarian data and study protocols; ethics guidelines; and new funding opportunities.

\section{CONCLUSION}

Humanitarian crises are having a bigger impact on human health now than at any time in recent history, yet the evidence base that informs humanitarian practice and policy is lacking. While research in these settings is especially challenging, there are reasons to be optimistic.

Awareness of the need for evidence in humanitarian health is growing among academics, humanitarians and research funders. In some protracted crises, such 
as for Syrian and Palestinian refugees, significant research efforts are building a formidable evidence base. And while there are limited research funding opportunities specific to humanitarian crises, several research funding agencies are supporting humanitarian research through other non-specific funding calls. Furthermore, humanitarian NGOs, such as Médecins Sans Frontières and the International Rescue Committee, are strengthening the internal research capacities of their staff and deepening partnerships with academic researchers. Several universities have established humanitarian programmes with research components, including Harvard, Johns Hopkins, the London School of Hygiene and Tropical Medicine and the American University of Beirut in Lebanon.

Still, humanitarian health needs remain formidable. Humanitarian health should be recognised as a key research priority and integral to progress in global health, not an outlier. Without this, we will never be able to comprehensively address high-burden global health needs nor achieve the ambitious SDGs.

Global health research funders must also recognise that researchers face unique challenges in conducting research in humanitarian crises and should consider strategies that address these challenges. These include investing in humanitarian health research capacity, supporting multisector partnerships, accounting for complex ethical and methodological issues and ensuring that local partners are engaged and play leadership roles whenever possible. Collectively, improving the evidence base for humanitarian health can improve the lives of millions of people worldwide.

Acknowledgements The publication of this paper was supported by the Fogarty International Center of the US National Institutes of Health. We thank the Planning Committee and participants in a workshop on Advancing Health Research in Humanitarian Crises, hosted by the Fogarty International Center on 9-11 April 2018, for their input.

Contributors All authors contributed to the conceptualisation of the manuscript with leadership from BAK and IN. ASM drafted the main text and all other authors reviewed and contributed additional content to further develop the text. All authors have read and agreed to the contents of the final draft of the manuscript.

Funding The authors have not declared a specific grant for this research from any funding agency in the public, commercial or not-for-profit sectors.

Competing interests None declared.

Patient consent for publication Not required.

Provenance and peer review Not commissioned; externally peer reviewed.

Data availability statement There are no data in this work.

Open access This is an open access article distributed in accordance with the Creative Commons Attribution Non Commercial (CC BY-NC 4.0) license, which permits others to distribute, remix, adapt, build upon this work non-commercially, and license their derivative works on different terms, provided the original work is properly cited, appropriate credit is given, any changes made indicated, and the use is non-commercial. See: http://creativecommons.org/licenses/by-nc/4.0/.

\section{ORCID iD}

Amit S Mistry http://orcid.org/0000-0001-6206-3793

\section{REFERENCES}

1 Bahgat K, Dupuy K, Østby G, et al. Children and armed conflict: what existing data can tell us. Oslo: Peace Research Institute Oslo (PRIO), 2018.

2. United Nations High Commissioner for Refugees (UNHCR). Global trends: forced displacement in 2018. Geneva United Nations; 2019.

3. Centre for Research on the Epidemiology of Disasters (CRED). Natural disasters 2017. Brussels CRED; 2018.

4. United Nations Office for the Coordination of Humanitarian Affairs (UNOCHA). World humanitarian data and trends 2018. Geneva United Nations; 2018.

5. United Nations High Commissioner for Refugees (UNHCR). Global trends: forced displacement in 2017. Geneva United Nations; 2018.

6. Organisation for Economic Co-operation and Development (OECD) States of fragility 2015: meeting post-2015 ambitions. Paris OECD; 2015.

7. The World Bank. World development report 2011: conflict, security, and development. Washington, DC The World Bank; 2011.

8 El-Zein A, DeJong J, Fargues P, et al. Who's been left behind? why sustainable development goals fail the Arab world. The Lancet 2016;388:207-10.

9. United Nations Office for Disaster Risk Reduction. Sendai Framework for Disaster Risk Reduction 2015-2030. Geneva United Nations; 2015.

10 Akil L, Ahmad HA. The recent outbreaks and reemergence of poliovirus in war and conflict-affected areas. Int $J$ Infect Dis 2016;49:40-6.

11 Grillet ME, Hernandez-Villena JV, Llewellyn MS, et al. Venezuela's humanitarian crisis, resurgence of vector-borne diseases, and implications for spillover in the region. Lancet Infect Dis 2019.

12. Inter-Agency Standing Committee (IASC) Reference Group for Mental Health and Psychosocial Support in Emergency Settings. Recommendations for conducting ethical mental health and psychosocial research in emergency settings; 2014.

13 Checchi F, Warsame A, Treacy-Wong V, et al. Public health information in crisis-affected populations: a review of methods and their use for advocacy and action. The Lancet 2017;390:2297-313.

14 Guha-Sapir D, Checchi F. Science and politics of disaster death tolls. BMJ 2018;362.

15. Knox Clarke P, Darcy J. Insufficient evidence? the quality and use of evidence in humanitarian action. ALNAP study. London ALNAP; 2014.

16 Blanchet K, Ramesh A, Frison S, et al. Evidence on public health interventions in humanitarian crises. The Lancet 2017;390:2287-96.

17 Rid A, Emanuel EJ. Ethical considerations of experimental interventions in the Ebola outbreak. The Lancet 2014;384:1896-9.

18. Integrating clinical research into epidemic response. The Ebola experience. Washington, D.C.: National Academies of Sciences, Engineering, and Medicine, 2017.

19. United Nations Office for the Coordination of Humanitarian Affairs (UNOCHA). Global humanitarian overview 2019. Geneva United Nations; 2019.

20 Perakslis ED. Using digital health to enable ethical health research in conflict and other humanitarian settings. Confl Health 2018;12:23.

21 Allden K, Jones L, Weissbecker I, et al. Mental health and psychosocial support in crisis and conflict: report of the mental health Working group. Prehosp Disaster Med 2009;24:s217-27.

22 Evidence Aid Priority Setting Group. Prioritization of themes and research questions for health outcomes in natural disasters, humanitarian crises or other major healthcare emergencies. PLoS Curr 2013;5.

23 Morof DF, Kerber K, Tomczyk B, et al. Neonatal survival in complex humanitarian emergencies: setting an evidence-based research agenda. Confl Health 2014;8:8.

24. Alliance for Child Protection in Humanitarian Action. Setting the global research agenda for child protection in humanitarian contexts: briefing note; 2017. https://alliancecpha.org/en/child-protectiononline-library/briefing-note-setting-global-research-agenda-childprotection

25 Tol WA, Patel V, Tomlinson M, et al. Research priorities for mental health and psychosocial support in humanitarian settings. PLoS Med 2011;8:e1001096.

26 Aebischer Perone S, Martinez E, du Mortier S, et al. NonCommunicable diseases in humanitarian settings: ten essential questions. Confl Health 2017;11:17.

27 Akik C, Ghattas H, Mesmar S, et al. Host country responses to noncommunicable diseases amongst Syrian refugees: a review. Confl Health 2019;13:8.

28. Inter-Agency Working Group on Reproductive Health in Crisis. Workshop on sexual and reproductive health research priorities 
in humanitarian settings meeting report; 2018. http://iawg.net/ resource/srh-workshop/

29 Hunt M, Schwartz L, Pringle J, et al. A research agenda for humanitarian health ethics. PLoS Curr 2014;6.

30 Woodward A, Sondorp E, Witter S, et al. Health systems research in fragile and conflict-affected states: a research agenda-setting exercise. Health Res Policy Sys 2016;14.

31 Bryant RA, Gallagher HC, Gibbs L, et al. Mental health and social networks after disaster. AJP 2017;174:277-85.

32 Kohrt BA, Worthman CM, Adhikari RP, et al. Psychological resilience and the gene regulatory impact of posttraumatic stress in Nepali child soldiers. Proc Natl Acad Sci U S A 2016;113:8156-61.

33 de Jong JTVM, Berckmoes LH, Kohrt BA, et al. A public health approach to address the mental health burden of youth in situations of political violence and humanitarian emergencies. Curr Psychiatry Rep 2015;17:60.

34 Levine AC. Academics are from Mars, humanitarians are from Venus: finding common ground to improve research during humanitarian emergencies. Clinical Trials 2016;13:79-82.
35. Habib RR. Ethical, methodological, and contextual challenges in research in conflict settings: the case of Syrian refugee children in Lebanon. Confl Health 2019;13:29.

36 Acharya B, Maru D, Schwarz R, et al. Partnerships in mental healthcare service delivery in low-resource settings: developing an innovative network in rural Nepal. Global Health 2017;13:2.

37 Kohrt BA, Upadhaya N, Luitel NP, et al. Authorship in global mental health research: recommendations for collaborative approaches to writing and publishing. Ann Glob Health 2014;80:134-42.

38 Chiumento A, Rahman A, Frith L, et al. Ethical standards for mental health and psychosocial support research in emergencies: review of literature and current debates. Global Health 2017;13:8.

39 Jordans MJD, Pigott H, Tol WA. Interventions for children affected by armed conflict: a systematic review of mental health and psychosocial support in low- and middle-income countries. Curr Psychiatry Rep 2016;18:9. 